\title{
Educational Guidelines for Caregivers of Cancer Patients toward Palliative Care
}

\author{
Sabah Abd EL-Moatamed Morsy', Howyida Sadek Abd EL-Hameed ${ }^{2}$ and Doaa Mohamed \\ Sobhy El- Sayed ${ }^{3}$
}

(1) Ph.D. student of Public Health Nursing, Faculty of Nursing - Benha University, Egypt,(2) Professor of Community Health Nursing, Faculty of Nursing - Benha University, Egypt and (3) Assistant Professor of Community Health Nursing, Faculty of Nursing - Benha University, Egypt

\begin{abstract}
Background: Palliative care is a specialized medical care for people living with a serious illness such as cancer. Aim of study: Was to evaluate the effect of educational guidelines on caregivers of cancer patients toward palliative care. Research design: A quasi - experimental research design was utilized in carrying out this study. Setting: This study was conducted at the Oncology Center at Nasser Institute Hospital Affiliated to Ministry of Health. Sample: A simple random sample was used to select 140 patients according to inclusion criteria from total 1400. Tools of data collection: Data were collected by using three tools. I: An interviewing questionnaire to assess the socio demographic characteristics of the studied patients, the medical history of patients, the socio demographic characteristics of caregivers, and the caregivers' knowledge about cancer and palliative care. II: Likert scale designed to assess the studied caregivers' attitude toward palliative care and III: Practices assessment sheet designed to assess the caregivers' practices toward palliative care. Results: $35.7 \%$ of the caregivers had good total knowledge regarding cancer before the educational guidelines implementation which increased to $62.2 \%$ after the educational guidelines implementation, $30.0 \%$ of them had good total level of knowledge regarding palliative care before the educational guidelines implementation which increased to $63.6 \%$ after the educational guidelines implementation, $25.0 \%$ of them had positive total level of attitude regarding palliative care before the educational guidelines implementation which increased to $70.0 \%$ after the educational guidelines implementation, and $35.7 \%$ of them had satisfactory total level of practices regarding palliative care before the educational guidelines implementation which increased to $77.1 \%$ after the educational guidelines implementation. Conclusion: The educational guidelines succeeded in improving the studied caregivers' knowledge, reported practices, and attitude regarding palliative care. Recommendations: Provide training courses for caregivers regarding palliative care
\end{abstract}

Key words: Cancer, Caregivers, Palliative care.

\section{Introduction:}

Cancer is the generic term for a large group of diseases characterized by a rapid creation of abnormal cells that grow beyond the usual boundaries and has the ability to metastasize to other organs. Cancer can start almost anywhere in the human body and made up of trillions of cells. Normally, human cells

grow and multiply (through a process called cell division) to form new cells as the body needs. When the cells grow old or become damaged, the cells die, and new cell take place. Sometimes the orderly process breaks down, and abnormal or damaged cells grow and multiply. The cells may form tumors, which are lumps of tissue. Tumors can be cancerous or 
not cancerous (National Cancer Institute (NCI), 2021).

Worldwide, an estimated 19.3 million new cancer cases and almost 10.0 million cancer deaths occurred in 2020.The global cancer burden is expected to be 28.4 million cases in 2040, a $47 \%$ rise from 2020 , with a larger increase in transitioning (64\% to $95 \%$ ) versus transitioned (32\% to $56 \%$ ) countries due to demographic changes, although this may be further exacerbated by increasing risk factors associated with globalization and a growing economy (Sung et al., 2021).

Cancer symptoms and treatment can negatively affect the patients' Quality of Life (QOL) because of the physical discomfort, mental stress, and economic pressure. Therefore, in 1990 the World Health Organization (WHO) introduced the Palliative Care (PC) initiative, which represents medical care focused on improving the QOL of patients with a severe illness by treating symptoms through an interdisciplinary approach (Gayatri et al., 2021).

Palliative care is a specialized medical care for people living with a serious illness such as cancer. PC is started with the onset of diagnosis and focused on relieving the symptoms and stress of illness. The goal of palliative care is to relieve suffering and provide the best possible quality of life for patients and their families. Symptoms may include pain, depression, shortness of breath, fatigue, constipation, nausea, loss of appetite, difficulty sleeping, and anxiety (Center of Advance Palliative Care, 2021).

The caregiver is a family members e.g. spouses, parents, children, siblings and others (e.g. friends, neighbors), who works with the health care team and has an important role in improving the patients' health and quality of life. Today, the caregivers can perform many tasks that used to be done in the hospital or in the doctors' office by health care providers. Caregiving includes everyday tasks such as helping the patient with medicines, doctor visits, meals, schedules, and health insurance matters. The caregivers' role also includes giving emotional and spiritual support, such as helping the patient deal with feelings and making hard decisions (Weis, 2021).

The community health nurses' role in palliative care have been outlined to include facilitating the cancer patients' access to supplies and medicines, routinely conducting assessments of the patients' physical, psychosocial and spiritual needs, developing a personal care plan in conjunction with family members, providing information and keeping records, and encouraging the family to keep the patient involved in the daily lives as much as possible (Macrae et al., 2021).

\section{Significance of the Study}

In Egypt, the National Cancer Registry Program revealed that the commonest cancer sites were liver, breast, and bladder $(23.8 \%$, 15.4 and $6.9 \%$, respectively) in both genders; liver and bladder $(33.6 \%$ and $10.7 \%$, respectively) in men; and breast and liver (32\% and $13.5 \%$, respectively) in females. According to WHO registry of oncology in Egypt, the number of cancer patients is expected to increase because of the increase in Egypt's population and increases in the average age, meaning that by 2050, the number of cancer patients in Egypt will be three times the current number (Kasem et al., 2021).

The situation of PC in the Middle East including Egypt, is limited and does not present a clear picture of the cultural context, and still in early stages and there are many obstacles to 


\section{Educational Guidelines for Caregivers of Cancer Patients toward Palliative Care}

its development, namely, lack of professional knowledge, inadequate support of policymakers, and lack of access to opioids and financial resources. Despite these challenges, providing services at the community level, support of nongovernmental organizations, using trained specialists and multi-disciplinary approach is an opportunity in Egypt (ElTaybani et al., 2020).

\section{Aim of study}

This study aimed to evaluate the effect of educational guidelines on caregivers of cancer patients toward palliative care.

\section{Research hypothesis}

The caregivers' knowledge, reported practices, and attitude will be improved after implementation of the educational guidelines toward palliative care.

\section{Subject and Methods \\ Research Design:}

A quasi - experimental research design was utilized in carrying out this study

\section{Setting:}

This study was conducted at the oncology center at Nasser institute hospital affiliated to Ministry of health. It provides general and special medical services that include outpatient clinics, radiotherapy, chemotherapy, blood transfusion, CT scan, MRI scan and PET scan. The oncology center consists of three floors; the first floor contains six outpatient clinics, clinic for triage, medical and 2 surgical clinic, clinic for pain management and radiology clinic, waiting areas for patients, one room for engineering who responsible about maintenance of radiation equipment and machines, another room for old files and radiation records, one room for physicians, PET scan unit, radiotherapy unit,
CT scan unit, two atomic scan unit, outpatient pharmacy.

The second floor consists of the day care unit (15 beds for blood transfusion), 36 beds for chemotherapy, inpatient pharmacy, waiting areas for patients, Hematology Clinic, CT scan unit, and MRI unit. The third floor consists of one room for a pediatric outpatient clinic, waiting areas for patients, libraries unit, reporting $\&$ recording unit.

\section{Sample:}

Simple random sample was used to select sample according to inclusion criteria. This number was representing $10 \%$ from the total number of caregivers who were attending with their cancer patients to the mentioned setting. The number of cancer patient attended to oncology clinics last year was 1400 according to statistic of oncology clinics of Nasser Institute for Research and Treatment Hospital 2018.

\section{Tools of data collection:}

Three different types of data collection tools were used to carry out this study namely: An interviewing questionnaire, Likert scale and Practices assessment sheet.

Tool 1-An interviewing questionnaire: It was developed by the researcher based on reviewing the related literatures and it was written in a simple clear Arabic language and consisted of two parts:

Part I: - This part included four portions:

A- Socio demographic characteristics of the studied patients. It consisted of seven questions related to age, sex, educational level, marital status, family size, occupation, monthly income.

B- Medical history of patients: It included four questions about (diagnosis duration of illness, type of treatment and signs \&symptoms). 


\section{Sabah Abd EL-Moatamed, HowyidaSadekAbd EL-Hameed and Doaa Mohamed Sobhy El- Sayed}

C- Socio demographic characteristics of caregivers. It consisted of twelve questions related to age, sex, educational level, marital status, occupation, natural of work, the kinship to patient, experience to work with cancer patient, health education about palliative care, source of health education, training about palliative care and duration of training.

D- Knowledge questionnaire sheet. It was developed by the researcher to assess the caregivers' knowledge toward 1cancer. It consisted of twelve questions. 2- Palliative care. It consisted of eleven questions.

\section{Scoring system:}

Knowledge score for each answer was given as follows: Correct and complete (2), Correct and incomplete (1) and Incorrect /don't know (0). Total score of knowledge $=46$, for each area of knowledge, the score of the items was summed-up and the total divided by the number of the items, giving a mean score for the part. These scores were converted into a percent score. The total knowledge score was considered good if the score of the total knowledge > $75 \%$ (>34points), considered average if it equals $50-75 \%$ (23-34points), and considered poor if it less than $50 \%(<$ 23points).

\section{Tool 2-Likert scale:}

It was adopted from (Ayed et al. 2015), modified and translated to Arabic by the researcher which included sixteen statements to assess the studied caregivers' attitude toward palliative care of cancer patient. This part measured pre and post the educational guidelines.

\section{Scoring system:}

A score for each response on questions of attitudes was given as follow: Always (2), sometimes (1) and rarely (0). Total score of attitude $=32$, the score of the items was summed-up and the total divided by the number of the items, giving a mean score for the part. These scores were converted into a percent score. The attitude was considered positive if the score of total attitudes $>75 \%$ (> 24 score), considered indifferent if it equals $50-75 \%$ (16 -24 points), and negative if it is $<50 \%$ (<16points).

\section{Tool 3- Practices assessment sheet:}

It was designed to assess the caregivers' practices toward palliative care of cancer patient as reported by them. It included four aspects of palliative care. (A) Psychological aspects of care which included seven steps, (B) Cultural aspects of care which included five steps, (C) Spiritual aspect of care which included five steps and (E) Ethical and legal aspects of care which included four steps. This part measured pre and post the educational guidelines.

\section{Scoring system:}

The score for each practice was given as follows: Done (1) and not done (0).

Total scores of practices $=61$, the total practices were considered satisfactory if the score of the total practices $\geq 60 \%$ ( $\geq 36$ score), and considered unsatisfactory if it is less than $60 \%$ (<36score).

\section{Tools validity:}

Content validity was done by five of the Faculty Staff Nursing experts from the Community Health Nursing Specialties who reviewed the tools for clarity, relevance, comprehensiveness, understanding, and applicability. There were minor modifications required 


\section{$\underline{\text { Educational Guidelines for Caregivers of Cancer Patients toward Palliative Care }}$}

\section{Reliability of tools:}

Reliability of the tools was done by using Cronbach's Alpha coefficient test which revealed that each of the three tools consisted of relatively homogenous items as indicated by the moderate to high reliability of each tool. The internal consistency of knowledge was 0.92 , attitudes was 0.89 , and 0.94 for practices.

\section{Pilot Study:}

A pilot study was conducted on 14 of caregivers who were attended with their cancer patients and represented $10 \%$ from the total number of caregivers and they were excluded from the study sample. The pilot study was aimed to assess the feasibility, clarity, and applicability of the tools also to determine the time needed for filling the structured questionnaire. According to the results obtained from data analysis, the modifications, correction, omission and addition were done. The tools lasted about 30 minutes to be filled.

\section{Field work:}

\section{An educational guideline was implemented through four phases:}

\section{Phase I: -Assessment phase:}

Based on the results obtained from the interviewing questionnaire and practices assessment sheet as well as literature review. The educational guideline developed by the researcher.

\section{Phase II: - Planning phase:}

The educational guideline was designed to achieve the objectives of the study.

\section{The general objective:}

Apply the educational guidelines for caregivers of cancer patients toward palliative care according to their actual educational needs in order to improve their knowledge, attitudes, and practices toward palliative care of cancer patients.

\section{Content of educational guidelines:}

The content of the educational guidelines was designed to meet the caregivers ' needs toward palliative care of cancer patients and it was consisted of the following: Meaning of cancer, causes of cancer, types of cancer, the most vulnerable groups for cancer, signs and symptoms of cancer, complications of cancer, methods of cancer diagnosis, cancer treatment methods and its complication, methods of cancer prevention, meaning of palliative care, palliative care recipients, aim of palliative care, the suitable time to start palliative care, aspects of palliative care, components of palliative care, advantages and disadvantages of palliative care, palliative care team, role of palliative care team, ethical principles of palliative care, the barriers of palliative care and apply the different aspects toward palliative care.

All the caregivers received the same guidelines content using the same teaching methods which included the following: Lectures / group discussion, brain storming and demonstration / re-demonstration.

The teaching aids: Suitable teaching aids were specially prepared for the intervention as follows; booklet and posters.

\section{Implementation phase:}

The study was conducted over a period of 5 months which started from July 2020 to the end of November 2020. Data was collected by interviewing the caregivers in the selected outpatient clinic at the Nasser Institute for Research and Treatment Hospital.

The researcher was attended three days/week (Saturday, Sunday and Tuesday) from 9:00 am to $12: 00$ mid - day.

Caregivers were divided into groups (twenty groups) each group contained 7Caregivers. The researcher was attended with 
one group /week, and the guidelines were discussed with them

The number of sessions was six (6) sessions of six (6) hours (4 hours theoretical and 2 hours practical). The duration of each session was 60 minutes, including the periods of discussion. The caregivers were present all the time of the intervention sessions and the duration of each session was variable, according to its contents as well as the caregivers' response.

An orientation to the educational guidelines and its process were presented. Each session started with a brief summary about what had been given through the previous session, then the objectives of the new topics, taking into consideration the use of simple language to suite the level of the caregivers.

Discussion, motivation and reinforcement during the educational guidelines sessions were used to enhance learning. Direct reinforcement in a form of copy of the intervention was given as a gift for each caregiver to use it as a future reference. All the caregivers were cooperative with the researcher and at the end of each session the caregivers participated in a discussion to correct any misunderstanding. Also, they were informed about the time of the next session.

\section{Phase IV: Evaluation of the educational guideline:}

Evaluation of the educational guidelines were done immediately at the end of it by using the same pre/post tools to evaluate the degree of improvement in the studied caregivers of cancer patients' knowledge, attitude, and practices toward palliative care.

\section{Statistical analysis:}

Statistical analysis was done by using Statistical Package for Social Sciences (SPSS) version 20. Data were collected, revised, coded, organized, tabulated, and analyzed using frequencies, number, percentage, mean scores, standard deviation and correlation coefficient. Data were presented in the form of tables and figures. Quantitative data was presented by mean $(\overline{\mathrm{X}})$ and standard deviation (SD). Qualitative data was presented in the form of frequency distribution tables, number and percent. It was analyzed by Chi- square test $\left(\mathrm{X}^{2}\right)$ \& correlation to detect the relation between the variables of the study (P-value).

Statistical significance was considered as follows:

- P-value $>0.05$ Not significant

- $\mathrm{P}$ - value $<0.05$ Significant

- P-value $<0.001$ Highly significant

\section{Results}

Table (1): Shows that, $35.7 \%$ of the studied patients aged from 38 to $<48$ years old with $\bar{X} \pm$ SD of $38.34 \pm 11.52,67.1 \%$ of them were females, and $35.0 \%$ of them had university education. As for the marital status, $43.6 \%$ of them were married, and $53.6 \%$ of the studied patients had from 3-5 members in their family with $\bar{X} \pm \mathrm{SD}$ of $4.74 \pm 1.27$. Concerning occupation, $58.6 \%$ of the studied patients were working, and $49.3 \%$ of them had enough monthly income.

Table (2): Illustrates that, $48.6 \%$ of the studied caregivers aged from 30 to $<40$ years old with $\bar{X} \pm$ SD of $39.21 \pm 6.29,83.6 \%$ of them were females, and $50.0 \%$ of them had secondary or technical education. As regards the marital status, $83.6 \%$ of them were married, and $92.1 \%$ of them were working. Regarding the nature of their work, $75.9 \%$ of them were employees, and $42.8 \%$ of them were the patients' husband/ wife, and $58.6 \%$ of them had less than five years of experience in working with cancer patient with $\bar{X} \pm S D$ of $5.28 \pm 3.92$. 


\section{Educational Guidelines for Caregivers of Cancer Patients toward Palliative Care}

Figure (1): Indicates that, $35.7 \%$ of the studied caregivers had good total knowledge regarding cancer before the educational guidelines implementation which increased to $62.2 \%$ after the educational guidelines implementation, while $50.0 \%$ of them had poor total knowledge before the educational guideline implementation which decreased to $17.1 \%$ after the educational guidelines implementation.

Figure (2): Demonstrates that, 30.0\% of the studied caregivers had good total level of knowledge regarding palliative care before the educational guidelines implementation which increased to $63.6 \%$ after the educational guidelines implementation, while $46.4 \%$ of them had poor total level of knowledge before the educational guideline implementation which decreased to $15.0 \%$ after the educational guidelines implementation.

Figure (3): Clarifies that, $25.0 \%$ of the studied caregivers had positive total level of attitudes regarding palliative care before the educational guidelines implementation which increased to $70.0 \%$ after the educational guidelines implementation, while $50.7 \%$ of them had negative total level of attitudes before the educational guidelines implementation which decreased to $15.7 \%$ after the educational guidelines implementation.

Figure (4): Describes that, $35.7 \%$ of the studied caregivers had satisfactory total level of practices regarding palliative care before the educational guidelines implementation which increased to $77.1 \%$ after the educational guidelines implementation, while $64.3 \%$ of them had unsatisfactory total level of practices before the educational guidelines implementation which decreased to $22.9 \%$ after the educational guidelines implementation.
Table (3): Indicates that, there were highly statistically significant positive correlations between the studied caregivers' total knowledge and both total attitudes and practices regarding palliative care before and after the educational guidelines implementation at $(\mathrm{P}<0.001)$. 
Table (1): Frequency distribution of the studied patients according to their socio demographic characteristics, $(n=140)$.

\begin{tabular}{|c|c|c|}
\hline Socio demographic characteristics & No. & $\%$ \\
\hline \multicolumn{3}{|l|}{ Age (years): } \\
\hline $18-<28$ & 28 & 20.0 \\
\hline $28-<38$ & 34 & 24.3 \\
\hline $38-<48$ & 50 & 35.7 \\
\hline $48+$ & 28 & 20.0 \\
\hline \multicolumn{3}{|l|}{ Mean \pm SD $\quad 38.34 \pm 11.52$} \\
\hline \multicolumn{3}{|l|}{ gender: } \\
\hline Male & 46 & 32.9 \\
\hline Female & 94 & 67.1 \\
\hline \multicolumn{3}{|l|}{ Educational level: } \\
\hline Don't read or write & 28 & 20.0 \\
\hline Basic education & 26 & 18.6 \\
\hline Secondary or technical education & 37 & 26.5 \\
\hline University education & 49 & 35.0 \\
\hline \multicolumn{3}{|l|}{ Marital status: } \\
\hline Single & 37 & 26.4 \\
\hline Married & 61 & 43.6 \\
\hline Divorced & 19 & 13.6 \\
\hline Widowed & 23 & 16.4 \\
\hline \multicolumn{3}{|l|}{ Family size: } \\
\hline$<3$ & 18 & 12.9 \\
\hline $3-5$ & 75 & 53.6 \\
\hline$>5$ & 47 & 33.6 \\
\hline \multicolumn{3}{|l|}{ Mean \pm SD $\quad 4.74 \pm 1.27$} \\
\hline \multicolumn{3}{|l|}{ Occupation: } \\
\hline Work & 82 & 58.6 \\
\hline Don't work & 58 & 41.4 \\
\hline \multicolumn{3}{|l|}{ Monthly income: } \\
\hline Enough and saving & 18 & 12.9 \\
\hline Enough & 69 & 49.3 \\
\hline Insufficient & 53 & 37.9 \\
\hline
\end{tabular}


Table (2): Frequency distribution of the studied caregivers according to their socio demographic characteristics, $(n=140)$.

Socio demographic characteristics

No.

Age (years):

$$
\begin{aligned}
& 20-<30 \\
& 30-<40 \\
& 40-<50
\end{aligned}
$$

\section{Mean \pm SD $\quad 39.21 \pm 6.29$}

gender:

Male

Educational level:

\begin{tabular}{|l|l|l|}
\hline Don't read and write & 4 & 2.9 \\
\hline Basic education & 35 & 25.0 \\
\hline Secondary or technical education & $\mathbf{7 0}$ & $\mathbf{5 0 . 0}$ \\
\hline University education & 31 & 24.1 \\
\hline
\end{tabular}

\section{Marital status:}

\begin{tabular}{|l|l|l|}
\hline Single & 19 & 13.6 \\
\hline Married & $\mathbf{1 1 7}$ & $\mathbf{8 3 . 6}$ \\
\hline Divorced & 1 & 0.7 \\
\hline Widowed & 3 & 2.1
\end{tabular}

\section{Occupation:}

\begin{tabular}{|l|l|l} 
Work & $\mathbf{1 2 9}$ & $\mathbf{9 2 . 1}$ \\
\hline Don't work & 11 & 7.9
\end{tabular}

The nature of work $(n=129)$ :

Employee

Free business

\begin{tabular}{|l|l|}
\hline $\mathbf{9 8}$ & $\mathbf{7 5 . 9}$ \\
\hline 31 & 24.1 \\
\hline
\end{tabular}

The kinship to patient:

\begin{tabular}{|l|l|l|} 
Husband/ wife & $\mathbf{6 0}$ & $\mathbf{4 2 . 8}$ \\
\hline Son/daughter & 27 & 19.3 \\
\hline Brother/sister & 26 & 18.6 \\
\hline Others & 27 & 19.3
\end{tabular}

Years of experience in working with cancer patient:

\begin{tabular}{|l|l|l}
$<5$ years & $\mathbf{8 2}$ & $\mathbf{5 8 . 6}$ \\
\hline $5-10$ & 31 & 22.1 \\
\hline 10 & 27 & 19.3 \\
\hline
\end{tabular}


$\underline{\text { Sabah Abd EL-Moatamed, HowyidaSadekAbd EL-Hameed and Doaa Mohamed Sobhy El- Sayed }}$

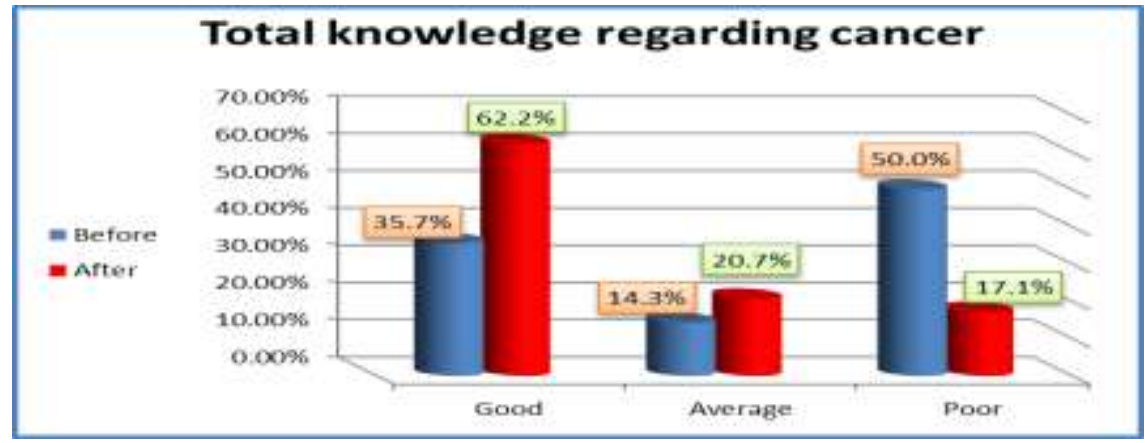

Figure (1): Percentage distribution of the studied caregivers' total level of knowledge regarding cancer before and after the educational guidelines implementation.

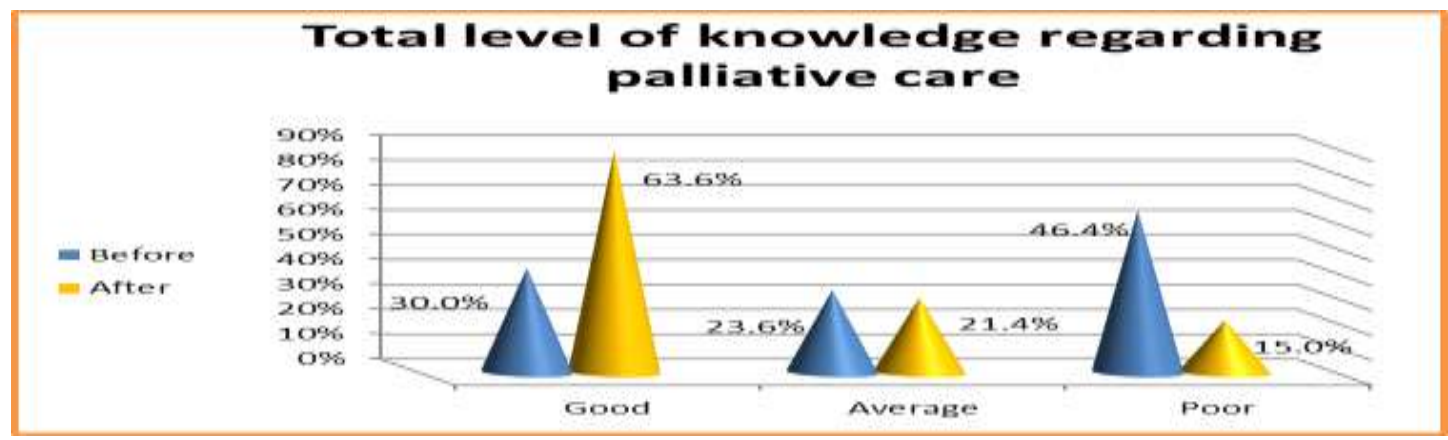

Figure (2): Percentage distribution of the studied caregivers' total level of knowledge regarding palliative care before and after the educational guidelines implementation.

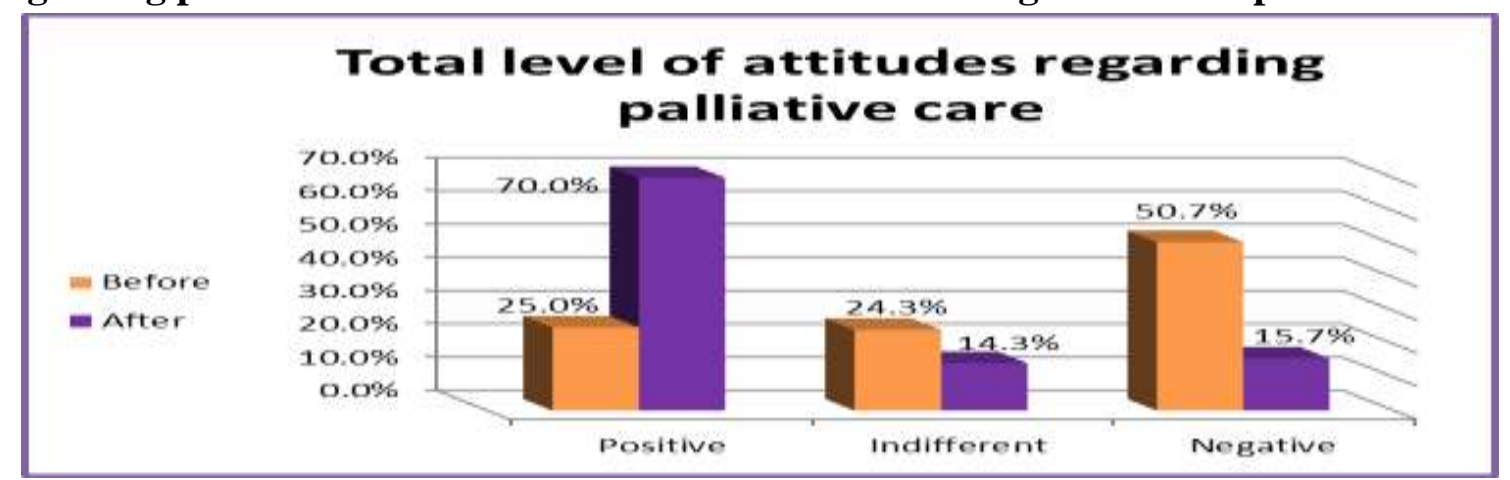

Figure (3): Percentage distribution of the studied caregivers' total level of attitudes regarding palliative care before and after the educational guidelines implementation.

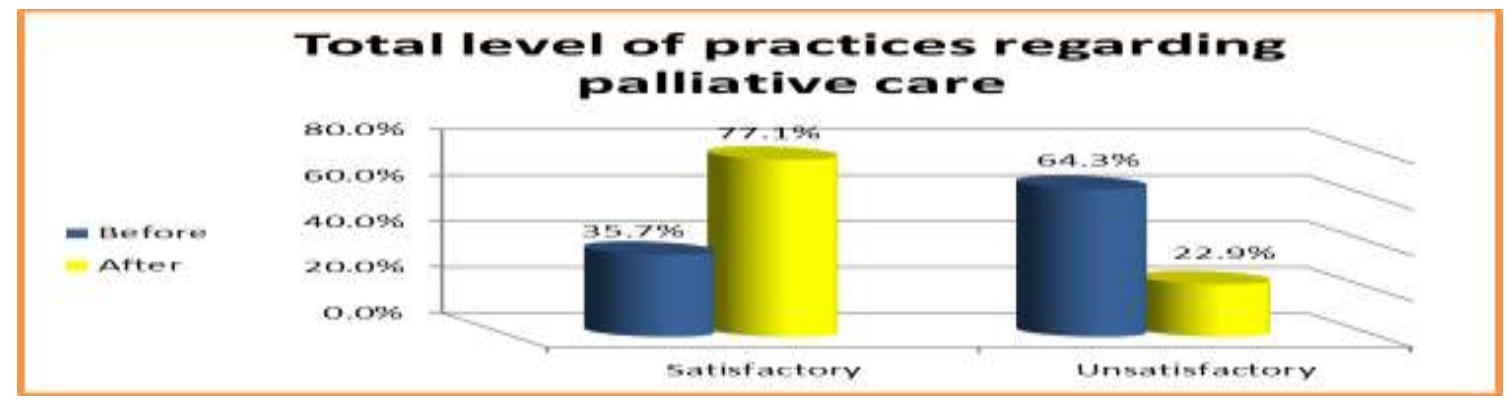

Figure (4): Percentage distribution of the studied caregivers' total level of practices regarding palliative care before and after the educational guidelines implementation. 
Table (3): Correlation between the studied caregivers' total knowledge and both total attitude and practices before and after the educational guidelines implementation, $(n=140)$.

\begin{tabular}{||l|c|c|c|c|}
\hline \multirow{2}{*}{ Items } & \multicolumn{4}{|c|}{ Total knowledge } \\
\cline { 2 - 5 } & \multicolumn{3}{|c|}{ Before } & \multicolumn{2}{c|}{ After } \\
\cline { 2 - 5 } & $\mathbf{r}$ & P-value & $\mathbf{R}$ & P-value \\
\hline \hline Total attitudes & 0.477 & $0.001^{* *}$ & 0.590 & $0.001^{* *}$ \\
\hline Total practices & 0.220 & $0.002^{*}$ & 0.378 & $0.001^{* *}$ \\
\hline
\end{tabular}

**Correlation is highly significant at the 0.001 level.

\section{Discussion:}

Palliative care is the active holistic care of patients with advanced, progressive illness. Management of pain and other symptoms and provision of psychological, social and spiritual support is paramount. The goal of palliative care is achievement of the best quality of life for patients and their families. Many aspects of palliative care are also applicable earlier in the course of the illness in conjunction with other treatments. Palliative care goes beyond the traditional medical model to focus on psychosocial issues, spiritual matters, medical decisionmaking, and on the relief of suffering in all its dimensions throughout a person's illness (Elshamy, 2019).

Regarding to socio - demographic characteristics of the studied patients, the current study illustrated that more one third of the studied patients aged from 38 to $<48$ years old with ${ }^{-} \mathrm{X} \pm \mathrm{SD}$ of $38.34 \pm 11.52$, this result disagreed with Ramasubbu et al. (2020), who studied "quality of life and factors affecting it in adult cancer patients undergoing cancer chemotherapy in a tertiary care hospital, India" and reported that $40 \%$ of patient aged more than 60 years, also in same line with Aboul Enien et al. (2018), who were in a study about health-related quality of life: impact of surgery and treatment modality in breast cancer, Egypt, as reported that $46.3 \%$ of age group of the studied patients were 50-60 years.
Regarding gender and marital status. The current study illustrated that more two thirds of them were females, more than twofifths of them were married, this result in same line with Nayak et al. (2017), who were in a study about "quality of life among cancer patients in Indian" and found that $(57.2 \%)$ were females, $(94.5 \%)$ were married,

Regarding family member, the current study showed that more than half of the studied patients had from 3-5 members in their family, this result in same line with Aboul Enien et al. (2018), who reported that $40 \%$ of studied patients their family 3-5 members. This might be due to the most of patients female and aware of the importance of family planning.

In relation to occupation, the present study illustrated that about three-fifths of the studied patients were working, this result is supported by Metwaly\&Hamad, (2019), who studied "the effect of palliative care program on nurses' performanceregarding prostate cancer and patients' outcomes, Egypt" as they reported that $56.7 \%$ of the studied patients were worked, this might be due to they need to cover the financial life's requirement or had desire for actualization.

Concerning income, the present study revealed that about half of the studied patients had enough monthly income, this result contradicted with Bayumi\& Mohamed (2019), who studied "factors affecting quality of Life among cancer patients with 
chemotherapy at Qena university hospital in upper Egypt", as reported that $78 \%$ of studied patients not had enough monthly income, this result might be due to the family members were $3 / 5$ and studied patients were working so the monthly income enough their requirement.

As Regard socio demographic characteristics of the studied caregivers, the present study Illustrated that, about half of the studied caregivers aged from 30 to $<40$ years old with ${ }^{-} \mathrm{X} \pm \mathrm{SD}$ of $39.21 \pm 6.29$, half of them had secondary or technical education, this result is supported by Nejad et al. (2016), who conducted a study about "the effects of a patient-caregiver education and follow-up Program on the breast cancer caregiver strain index, Iran" and reported that caregiver age $30-50$ years and $52 \%$ of them had secondary school. This result might be because this age enabling caregivers to provide care to their sick relatives and meet their requirement and satisfaction.

Also, this result illustrated that more than three quarters of the studied caregivers were females; this result agreed with Seo\&Park (2019), who studied "factors influencing caregiver burden in families of hospitalized patients with lung cancer, Korea" as reported that $75.7 \%$ of the studied caregivers were female. This result might be due to that female considered the first one in family to support and provide caring for all family members.

As regards the marital status of the studied caregiver, the current study revealed that more than three quarters of the studied caregiver were married, this result in same line with Yesilbalkan et al. (2017), as reported that $54.8 \%$ of caregivers were married, this result might be due the most of patients were married, the most of caregivers were their wives who caring their patients.
Concerning caregivers working, the present study demonstrated that most of studied caregivers were working and more than three quarters of them were employed, this study is disagreed with Burns et al. (2020), who reported that $41 \%$ of care givers were employed, while $59 \%$ unemployed, this might to help to cover the financial requirements of family.

Regarding the nature of their work, the current study revealed that more than three quarters of studied caregivers were employees, this result disagrees with Geddie, (2016) who studied family Care giver's knowledge, patient illness characteristics, and Unplanned Hospital Admissions in Older Adults with Cancer, Florida as reported that $50.7 \%$ of studied caregivers were unemployed, this result might be due to as the most of them had university education that enabled them to be employed.

Regarding kinship of caregivers to patients, the present study illustrated that more than two-fifths of the studied caregivers were the patients' husband/ wives, this result in same line with Seo\& Park (2019), as reported that $62.6 \%$ of studied caregivers were spouse, this result might be due to the husbands/ wives were the nearest one to provide care because they stay with them long time in the same household.

Regarding years of experience of caregivers in working with cancer patients, the present study revealed that more than half of the studied caregivers had less than five years of experience in working with cancer patients with ${ }^{-} \mathrm{X} \pm \mathrm{SD}$ of $5.28 \pm 3.92$, this result in similar a study carried out by Ugalde et al. (2018), about "understanding rural caregivers' experiences of cancer care when accessing metropolitan cancer services: a qualitative study. Australia" as reported that $53 \%$ of caregivers spent less than 5 years 
caring with cancer patients. This might be due to the duration of illness, of the studied patients was less than five years, so it is the same period of caregivers spent caring with cancer patients.

Concerning total level of knowledge regarding cancer before and after the educational guidelines implementation, the current study revealed that half of the studied caregivers had poor total level of knowledge before the educational guidelines implementation compared to less than one fifth after the educational guidelines implementation, this result in same line with Belgacem et al. (2016), who studied "A caregiver educational program improves quality of life and burden for cancer patients and their caregivers: A randomized clinical trial" , as reported that the caregiver $\mathrm{s}^{\prime}$ knowledge improved after educational program compared to before it, there was statistically significant relation.

Concerning total level of knowledge of caregivers regarding palliative care before and after the educational guidelines implementation, the current study revealed that less than half of studied care givers had poor total level of knowledge before the educational guidelines implementation which decreased to less one fifth after the educational guidelines implementation,this result is supported by Shah, et al. (2020), as reported that more half of the caregivers had enhanced understanding of the palliative care approach. They showed consistent understanding of two foundational aspects indicating correct knowledge .This might be due to concise presentation using a simple language and clear educational methods and instructional media.

The present study demonstrated that the studied caregivers had unsatisfactory total level of practices regarding palliative care before the educational guidelines implementation compared to satisfactory level after the educational guidelines implementation, this result congruent with Carrillo et al. (2021), who studied 'the effect of an educational intervention for family caregivers of individuals with cancer, in Colombia", as reported that the educational intervention is a strategy that increases skills for care at home, and reduces the burden on caregivers of people with cancer on the perception of burden among the family caregivers of patients with cancer in Tunisia and reported that there were significant relation between practices and age, gender, occupation.

Regarding Correlation between the studied caregivers' total knowledge and both total attitudes and reported practices before and after the educational guidelines implementation, the current study revealed that there were highly statistically significant positive correlations between the studied caregivers' total knowledge and both total attitudes and reported practices regarding palliative care before and after the educational guidelines implementation at $(\mathrm{P}<0.001)$, this result in same line with

\section{Conclusion:}

The educational guidelines succeeded in improving the studied caregivers' knowledge, reported practices, and attitude regarding palliative care. There were highly statistically significant positive correlations between the studied caregivers' total knowledge and both total attitudes and practices regarding palliative care before and after the educational guidelines implementation.

\section{Recommendations:}

- Provide training courses for caregivers regarding palliative care.

- The study should be replicated to include farther research. 
- Illustrated booklet should be distributed at outpatient clinics and included knowledge and practices about palliative care.

- Palliative care should be integrated into the healthcare system, include hospitals and the community awareness should be raised by using public media, community volunteers, public health centers, and nursing schools.

\section{References:}

Aboul Enien, M., Ibrahim, N., Makar, W., Darwish, D., and Gaber, M. (2018). Healthrelated quality of life: Impact of surgery and treatment modality in breast cancer, Egypt, 14 (5): Pp. 957-963.

\section{Ayed A.,Sayej S., Harazeneh L. Fashafsheh}

I. and Eqtait F.(2015).The nurses' knowledge and attitudes toward palliative care, journal of education and practice,6 (4), pp. 96

Bayumi, H.A. and Mohamed, H.S. (2019). Factors Affecting Quality of Life among Cancer Patients with Chemotherapy at Qena University Hospital in Upper Egypt, Journal of Nursing and Health Science (IOSR-JNHS e-ISSN: 2320-1959.p- ISSN: 2320-1940 Volume 5, Issue 6 Ver. I (Nov. - Dec. 2016), PP 168-173 IOSR(www.iosrjournals.org.

Belgacem, B., Guiguet-Auclair, C. Fedor, M. and Brugnon, D. (2016). A caregiver educational program improves quality of life and burden for cancer patients and their caregivers: A randomised clinical trial, European journal of oncology nursing: the official journal of European Oncology Nursing Society 17(6).

Burns, C., Craft , P. and Dixon, T. (2018). Family caregiver knowledge of treatment intent in a longitudinal study of patients with advanced cancer, Australia, Supportive Care in Cancer 11(10):629-37

Carrillo, G., Laguna, M. and Gómez, M. (2021). Effect of an Educational Intervention for Family Caregivers of Individuals with Cancer, Faculty of Nursing Teacher. National University of Colombia.
Center of Advance Palliative Care, (2021). What Is Palliative Care?. Available at: https://getpalliativecare.org/whatis/. Accessed on 6 June 2021.

Elshamy, K. (2019). Current Status of Palliative Care Nursing in Egypt: Clinical Implementation, Education and Research., J Palliat Care Med S5:005. doi:10.4172/21657386.1000S5005.

Eltaybani, S. Igarashi,A. and Mitani,N. (2020). Palliative and end-of-life care in Egypt: overview and recommendations for improvement International Journal of Palliative Nursing 26(6):284291DOI:10.12968/ijpn.2020.26.6.284Availabl e .net Accessed on August 2020.

Gayatri, D., Efremov, L., Kantelhardt, E., and Mikolajczyk, R. (2021). Quality of life of cancer patients at palliative care units in developing countries: systematic review of the published literature. Available at: https://link.springer.com/article/10.1007/s 11136-020-02633-z. Accessed on 1 July 2021.

Geddie, P. (2016). Family Care Giver Knowledge, Patient Illness Characteristics, and and Unplanned Hospital Admissions in Older

Kassem, N., Kassem, H., Kassem, L., and Hassan, M. (2021). Detection of activating mutations in liquid biopsy of Egyptian breast cancer patients using targeted next-generation sequencing: a pilot study. Journal of the Egyptian National Cancer Institute; 33(10): P.2.

Macrae, M., Fazal, O., and O'Donovan, J. (2021). Community health workers in palliative care provision in low-income and middle-income countries: a systematic scoping review of the literature. BMJ Journals 5(5): Pp. 1. http://dx.doi.org/10.1136/bmjgh2020-002368.

Metwaly, E.A. and Hamad, A.H. (2019). Effect of palliative care program on nurses' performance regarding prostate cancer and 
patients' outcomes , Zagazig University, Sharkia, Egypt 2019 | Volume : 16 | Issue : 3 | Page : 195-205.

National Cancer Institute, (2021). What is cancer?. Available at: https://www. Cancer .gov/about-cancer/ understanding/what-iscancer. Accessed on 5 June 2021.

Sung, H., Ferlay, J., Siegel, R., Laversanne, M., Soerjomataram, I., Jemal, A., and Bray, F. (2021). Global Cancer Statistics 2020: GLOBOCAN Estimates of Incidence and Mortality Worldwide for 36 Cancers in 185 Countries. CA Cancer Journal Clin; 71(3):Pp.209-249. doi: 10.3322/caac.21660. Available online at cancer journal.com.

Nayak, M.G., George, A., Mamidipudi, V., and Mathew, S. (2017). Quality of Life among Cancer Patients, 2017Indian Journal of $\begin{array}{lll}\text { Palliative Care 23(4):445 } & \end{array}$ DOI:10.4103/IJPC.IJPC_82_17

Nejad, Z., Aghdam, A. and Sanaat, Z. (2016). The Effects of a Patient-Caregiver Education and Follow-Up Program on the Breast Cancer Caregiver Strain Index, iran, Iranian Red Crescent Medical Journal;(18)3.

Ramasubbu, S., Pasricha, R., Nath, U., Rawat, V.,and Das, B. (2020). Quality of life and factors affecting it in adult cancer patients undergoing cancer chemotherapy in a tertiary care hospital, India, Volume4, Issue2
.Seo, Y., and Park, H., (2019). Factors influencing caregiver burden in families of hospitalised patients with lung cancer Korea , Volume28, Issue9-10 Pages 1979-1989.

Shah, S., Qaisar, F.,

Azam, I. and Mansoor ,K.(2020). Perceptions, knowledge and attitudes towards the concept and approach of palliative care amongst caregivers: a cross-sectional survey in Karachi, Pakistan, BMC Palliative Care volume 19, Article number: 180 (2020)

Ugalde, A., Blaschke, S.and Boltong, A., (2018). Understanding rural caregivers' experiences of

Weis, A., Pohlmann, S., Poss-Doering, R., Strauss, B., Ullrich, C., Hofmann, H., Ose, D., Winkler, E., Szecsenyi, J., and Wensing, M. (2021). Caregivers' role in using a personal electronic health record: a qualitative study of cancer patients and caregivers in Germany. Available at:https://bmcmedinformdecismak.biomedcen tral.com/articles/10.1186/s12911-020-01172-

4. Accessed on 1Juli 2021.

Yesilbalkan, O.U., OZER, S. and Ruzkar , U. (2017). Cancer Pain: Knowledge and Experiences from the Perspective of the Patient and their Family Caregivers, turkey, ARC Journal of Nursing and Healthcare, Volume-3 Issue-3, 2017, Page No: 26-34, DOI: $\quad$ http://dx.doi.org/10.20431/24554324.0303004 


\section{ارشادات تعليمية لمقدمى الرعاية لمرضى السرطان تجاه الرعاية التلطيفية صباح عبد المعتمدمرسى - هو يدا صادق عبدالحميد- دعاء محم صبحي السيد}

الرعاية التلطيفية هى رعاية طبية خاصة للاشخاص الذين يعانون من امر اض خطيرة مثل السرطان، لذلك

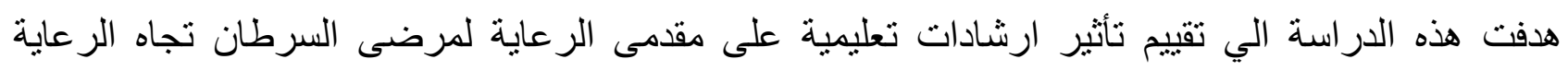

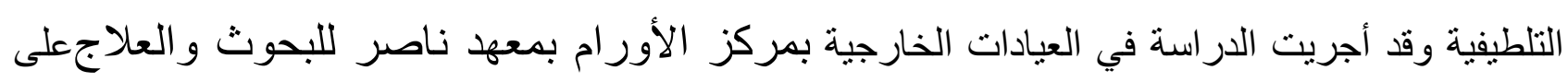

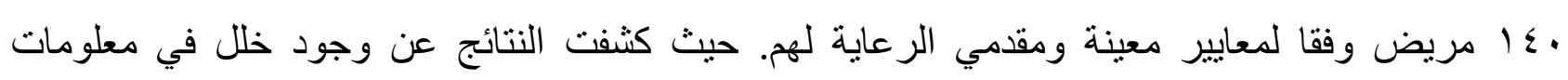

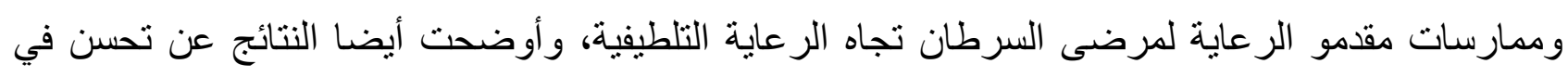

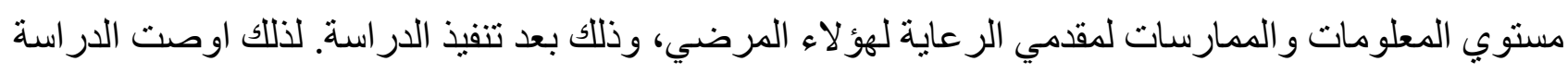
بضرورة عمل دورات تدريبية لمقدمي الرعاية تجاه الرعاية التلطيفية 